Gut and Liver, Vol. 11, No. 1, January 2017, pp. 27-37

\title{
25 Years of Proton Pump Inhibitors: A Comprehensive Review
}

\author{
Daniel S. Strand ${ }^{1}$, Daejin Kim² , and David A. Peura ${ }^{1}$ \\ ${ }^{1}$ Division of Gastroenterology and Hepatology, University of Virginia, Charlottesville, VA, USA, and ${ }^{2}$ Division of Gastroenterology, Daegu \\ Fatima Hospital, Daegu, Korea
}

Proton pump inhibitors (PPIs) were clinically introduced more than 25 years ago and have since proven to be invaluable, safe, and effective agents for the management of a variety of acid-related disorders. Although all members in this class act in a similar fashion, inhibiting active parietal cell acid secretion, there are slight differences among PPIs relating to their pharmacokinetic properties, metabolism, and Food and Drug Administration (FDA)-approved clinical indications. Nevertheless, each is effective in managing gastroesophageal reflux disease and uncomplicated or complicated peptic ulcer disease. Despite their overall efficacy, PPIs do have some limitations related to their short plasma half-lives and requirement for meal-associated dosing, which can lead to breakthrough symptoms in some individuals, especially at night. Longeracting PPIs and technology to prolong conventional PPI activity have been developed to specifically address these limitations and may improve clinical outcomes. (Gut Liver 2017;11:27-37)

Key Words: Proton pump inhibitors; Review; Pharmacokinetics; Indications; Risk

\section{INTRODUCTION}

Since the introduction of omeprazole in 1989, proton pump inhibitors (PPIs) have steadily become the mainstay in treatment of acid-related disorders. When compared with earlier agents such as histamine ${ }_{2}$-receptor antagonists $\left(\mathrm{H}_{2} \mathrm{RAs}\right)$, synthetic prostaglandin analogs, and anticholinergics, PPIs have demonstrated consistent patient tolerance, excellent safety, and generally superior acid suppressing capability than prior agents. ${ }^{1,2}$

As of 2015, there are six PPIs approved by the United States Food and Drug Administration (FDA) (Table 1). ${ }^{3}$ Adoption of PPI use has been widespread among primary care providers, and their presence is ubiquitous within the armamentarium of the modern gastroenterologist. For most, this class of drugs represents the first choice for treatment of esophagitis, nonerosive reflux disease (NERD), peptic ulcer disease (PUD), prevention of nonsteroidal anti-inflammatory drugs (NSAID) associated ulcers, Zollinger-Ellison syndrome (ZES), and functional dyspepsia. ${ }^{4-6}$ In combination with antibiotics, PPIs are also an integral part of eradication therapy for Helicobacter pylori. ${ }^{7}$

Despite an excellent safety profile throughout their first two decades of use, the nearly universal popularity of PPIs has prompted several concerns about both their short- and longterm effects. ${ }^{89}$ This review will examine the pharmacokinetics and pharmacodynamics of these drugs and provide an update on both the clinical use of and remaining challenges with PPIs.

\section{WHAT ARE PPIS AND HOW DO THEY WORK?}

All currently approved PPIs are benzimidazole derivatives: heterocyclic organic molecules that include both a pyridine and benzimidazole moiety linked by a methylsulfinyl group. The prototypical example of this structure, omeprazole, was the first clinically useful PPI. Subsequently introduced drugs include lansoprazole, pantoprazole, rabeprazole and the stereo-isomeric compounds esomeprazole and dexlansoprazole. ${ }^{10}$ Although each of these drugs has different substitutions on their pyridine and/ or benzimidazole rings, in general they are remarkably similar in their pharmacological properties.

More recently, the novel imidazopyridine PPI, tenatoprazole has undergone preliminary preclinical and clinical evaluation. Though not yet approved for clinical use, this new subset of PPI with a prolonged half-life may ultimately offer advantages over its benzimidazole cousins. ${ }^{10}$

PPIs are membrane permeable, acid-labile weak bases. In order to prevent premature activation and degradation by luminal gastric acid, these drugs are packaged in a variety of delivery systems. These include enteric-coated tablets, gelatin capsules,

\section{Correspondence to: Daniel S. Strand}

Division of Gastroenterology and Hepatology, University of Virginia, P0 Box 800708, Charlottesville, VA 22908, USA

Tel: +1-434-297-7207, Fax: +1-434-244-7590, E-mail: DSS7A@Virginia.edu

Received on October 5, 2015. Accepted on February 7, 2016. Published online November 14, 2016

pISSN 1976-2283 eISSN 2005-1212 https://doi.org/10.5009/gnl15502

@ This is an Open Access article distributed under the terms of the Creative Commons Attribution Non-Commercial License (http://creativecommons.org/licenses/by-nc/4.0) which permits unrestricted non-commercial use, distribution, and reproduction in any medium, provided the original work is properly cited. 
Table 1. Commercially Available Proton Pump Inhibitors in the United States

\begin{tabular}{|c|c|c|c|c|c|}
\hline Drug & Dosages, mg & IV & Liquid or suspension & Generic & Over-the-counter \\
\hline Omeprazole & $10,20,40$ & Yes & No & Yes & Yes \\
\hline Esomeprazole & 20,40 & Yes & Yes & Yes & Yes \\
\hline Lansoprazole & 15,30 & Yes & Yes & Yes & Yes \\
\hline Dexlansoprazole & 30,60 & No & No & No & No \\
\hline Pantoprazole & 20,40 & Yes & Yes & Yes & No \\
\hline Rabeprazole & 20 & No & No & Yes & No \\
\hline
\end{tabular}

Table 2. Pharmacokinetic Properties of Proton Pump Inhibitors

\begin{tabular}{|c|c|c|c|c|c|c|}
\hline & Omeprazole & Esomeprazole & Lansoprazole & Dexlansoprazole & Pantoprazole & Rabeprazole \\
\hline Bioavailability, \% & $30-40$ & $64-90$ & $80-85$ & - & 77 & 52 \\
\hline Time to peak plasma level (tmax, hr) & $0.5-3.5$ & 1.5 & 1.7 & $1-2,4-5$ & $2-3$ & $2-5$ \\
\hline Protein binding, $\%$ & 95 & 97 & 97 & 96 & 98 & 96.3 \\
\hline Half-life, hr & $0.5-1$ & $1-1.5$ & 1.6 & $1-2$ & $1-1.9$ & $1-2$ \\
\hline Primary excretion & Hepatic & Hepatic & Hepatic & Hepatic & Hepatic & Hepatic \\
\hline \multirow[t]{2}{*}{ Liver metabolism } & CYP2C19 & CYP2C19 & CYP2C19 & CYP2C19 & CYP2C19 & CYP2C19 \\
\hline & & & & CYP3A4 & CYP3A4 & \\
\hline
\end{tabular}

or coated granules supplied as a powder for suspension. They also may be packaged in combination with bicarbonate to confer temporary luminal $\mathrm{pH}$ neutralization. Once clear of the stomach, PPIs are absorbed in the proximal small bowel. There are also intravenous (IV) formulations available for lansoprazole, pantoprazole, and esomeprazole, which provide immediate acid suppression and are well suited for hospitalized patients in whom the oral route of administration is not appropriate. ${ }^{10}$ The serum half-life of single release PPIs is extremely short (1 to 2 hours), though considerable effort has been made to develop dual release/or delayed release formulations to counteract this short-coming. ${ }^{11,12}$ Imidazopyridines such as tenatoprazole, which have a serum half-life of 7 hours, may also overcome this weakness and potentially demonstrate added clinical benefit in the future. ${ }^{10}$

Once absorbed, circulation transits the PPIs to activated gastric parietal cells where they concentrate within the acidic secretory canaliculi. Here, the PPI undergoes acid-catalyzed cleavage of a chiral sulfoxide bond (except esomeprazole and dexlansoprazole which are nonchiral) into active sulfenic acid and/or sulfonamide. These compounds then bind covalently to cysteine residues on the $\mathrm{H}+/ \mathrm{K}+$ ATPase and act to inhibit acid secretion until replacement pumps can be synthesized (up to 36 hours). ${ }^{10}$ Although frequently considered equivalently effective with respect to clinical parameters, the specific pharmacologic properties among individual PPIs are somewhat different (Table 2). ${ }^{13}$

PPIs require the active canaliculi expression of $\mathrm{H}+/ \mathrm{K}+$ ATPases for binding which occurs in response to a meal. During a single meal, neither all parietal cells nor all of its proton pumps are active. Only about two-thirds of proton pumps are inhibited by a single PPI dose, which leaves up to one-third of pumps uninhibited. With future meals, as previously inactive enzymes are recruited into the secretory canaliculi, proton exchange will again increase (though attenuated). This physiology is the rationale both for preprandial dosing (important due to short serum half-life) and the observation of escalating pharmacologic efficacy of PPIs after multiday treatment. ${ }^{10}$

PPIs are highly protein bound and subject to degradation by hepatic P450 cytochromes. Although the CYP2C19 pathway is dominant overall, individual agents have variations which have led to concerns over efficacy and drug-drug interaction. ${ }^{14}$ Omeprazole and its stereo-isomer esomeprazole are metabolized almost entirely by CYP2C19, thereby offering the greatest potential for interaction with other drugs. Rabeprazole and lansoprazole/dexlansoprazole are also metabolized by CYP2C19, but they possess significant affinity for CYP3A4. Interactions appear less significant with these agents, perhaps owing to this difference. Pantoprazole, on the other hand, is primarily degraded by CYP2C19 0-demethylation and sulfate conjugation which results in the lowest potential for cytochrome induction or inhibition among the benzimidoles. ${ }^{15}$ It is our practice to favor pantoprazole or lansoprazole/dexlansoprazole in patients where this interplay of drug metabolism is a primary concern (i.e., patients with high risk for cardiovascular events who are on clopidogrel). Following hepatic metabolism, the ultimate excretion of most benzimidoles is renal, though lansoprazole/dexlansoprazole are also excreted via the biliary tree. ${ }^{6}$ While controversial, there are data to suggest that patients who are genetically rapid drug metabolizers, a situation more commonly encountered in Europe 
and North American, may be less likely to fully respond to their PPI treatment, especially $H$. pylori eradication than slower metabolizers of the drugs. ${ }^{15}$

\section{CLINICAL ADVANTAGES OF PPIs}

Gastric acid secretion is a multifactorial and complex process regulated by at least three different stimuli upon the parietal cell. These pathways include the paracrine elaboration of gastrin and histamine, as well as the actions of postganglionic muscarinic acetylcholine. Unlike anticholinergics and histamine2-receptor blockers, PPIs inhibit the final common pathway of acid secretion (the H/K ATPase) in response to any and all stimulation of the parietal cell. ${ }^{1,16}$

The PPIs represent the most potent inhibitors of gastric acid secretion available since, as noted above, they directly block the acid pump itself. Their superior biochemical effect compared with $\mathrm{H}_{2} \mathrm{RAs}$ is based upon their ability to reliably maintain intragastric $\mathrm{pH}>4$ for between 15 and 21 hours daily, as compared to only 8 hours for $\mathrm{H}_{2}$ RAs. ${ }^{16}$ In addition to being more long lasting, the effectiveness of PPIs is also superior with respect to postprandial and nocturnal intragastric $\mathrm{pH}$ control, which is of clinical importance in some patients. ${ }^{17}$ This effect of PPIs is also maintained over the long-term without the need for dose escalation. In contrast, tachyphylaxis may occur with $\mathrm{H}_{2} \mathrm{RAs}$ as rapidly as within 3 to 5 days of regular use. ${ }^{18}$ While the short-term implications of this difference may not be relevant, consistent use of $\mathrm{H}_{2} \mathrm{RAs}$ over a period of weeks to months may reduce their acid-suppressing effect nearly in half. ${ }^{19}$

\section{GENERAL CLINICAL USES OF PPIS}

\section{Healing of PUD}

While the underlying pathophysiology of gastric and duodenal ulcer disease is disparate, acid suppression remains the mainstay of treatment for both conditions. In both cases, the sustained neutralization $(\mathrm{pH}>3$ ) of gastric acid over 18 to 20 hours per day is an important determinant in healing. ${ }^{2,20}$

Clinical trials have consistently shown superior healing rates for gastroduodenal ulcers with PPI therapy than with $\mathrm{H}_{2} \mathrm{RAs}$. A meta-analysis which included 30 double-blind prospective trials of omeprazole ( $20 \mathrm{mg}$ daily) compared with either ranitidine or cimetidine demonstrated an overall therapeutic gain of 15.2\% in healing for duodenal ulcer $(\mathrm{p}<0.001)$ and 9.9\% for gastric ulcer $(\mathrm{p}<0.005)$ after only 2 weeks of treatment. In addition, a greater percentage of patients were also free of symptoms at first follow-up when treated with PPIs. ${ }^{21}$ Pooled data from 384 randomized controlled trials (RCTs) which included a total of 44,870 patients concluded that omeprazole was significantly more effective $(\mathrm{p}=0.001)$ than $\mathrm{H}_{2} \mathrm{RAs}$ in achieving ulcer healing, with overall rates of $80.8 \%$ and $74.7 \%$, respectively. ${ }^{22}$ Similar results with lansoprazole, ${ }^{23}$ rabeprazole, ${ }^{24}$ and pantoprazole ${ }^{25}$ confirm a class advantage in favor of PPIs.

After initial healing, maintenance therapy is an important consideration in high-risk patient groups such as those with PUD related complications, recurrences, or $H$. pylori negative ulcers. In a RCT including 195 patients, 20 mg of omeprazole given 3 days per week (q AM Friday through Sunday) reduced the incidence of recurrent duodenal ulcer when compared to placebo from $67 \%$ to $23 \%(\mathrm{p}<0.001){ }^{26}$ There are similar data for maintenance and prevention with lansoprazole $(15 \mathrm{mg}){ }^{27}$ Although clinical trials describe dosing of PPIs for maintenance for up to 12 months, the ideal duration of therapy is not known and prolonged treatment may be unnecessary if $H$. pylori is eradicated. It should also be noted that the continuous use of $\mathrm{H}_{2} \mathrm{RAs}$ are similarly effective at preventing ulcer recurrence compared to placebo ( $20 \%$ to $25 \%$ vs $60 \%$ to $90 \%$ ). ${ }^{28}$ We favor the use prolonged use of PPIs when coincident clinical concerns exist (e.g., persistent symptoms), when $\mathrm{H}_{2} \mathrm{RAs}$ have proven ineffective, in the setting of NSAID associated or non-H. pylori related ulcer, or when there have been ulcer-related complications (e.g., perforation and fibrosis) at the outset.

\section{Peptic ulcer related gastrointestinal bleeding}

Upper gastrointestinal (UGI) bleeding due to PUD is an important emergency medical condition which results in very high patient morbidity, health care costs, and mortality. ${ }^{29,30}$ While rapid assessment, best supportive care, and prompt endoscopic diagnosis and hemostasis are the mainstays of modern societal recommendations, ${ }^{30-32}$ the method and dose of antisecretory PPI therapy remains an important consideration. A Cochrane systematic review of six high-quality RCTs $(n=2,223)$ demonstrated that there was no improvement in overall mortality $(6.1 \%$ vs $5.5 \%$; odds ratio $[\mathrm{OR}]=1.12,0.72-1.73)$, rebleeding $(13.9 \%$ vs $16.6 \%$; OR=0.81, $0.61-1.09$ ), or surgery $(9.9 \%$ vs $10.2 \%$; $\mathrm{OR}=0.96,0.68-1.35)$ in patients who received pre-endoscopic PPI therapy. ${ }^{33}$ Despite this lack of improvement in hard outcomes, preadministration of PPI was noted to reduce the proportion of patients who had high-risk stigmata of hemorrhage by Forrest classification at the time of initial endoscopic exam (37.2\% vs 46.5\%; OR=0.67, 0.54-0.84). Furthermore, an analysis of patients in trials where endoscopic hemostatic therapy was inconsistently used, early PPI therapy was associated with reduced rebleeding $(\mathrm{OR}=0.38,0.18-0.81)$ and the need for surgery $(\mathrm{OR}=0.62,0.44-0.88)$. Given these data, along with the favorable risk profile of early PPI use, it is our practice to initiate a high dose IV bolus (pantoprazole or esomeprazole) and continuous infusion until endoscopic diagnosis can be ascertained. After endoscopy, the continuation of treatment and dose can be tailored to the identified source of bleeding.

Despite controversy over pre-endoscopic antisecretory therapy, there is solid agreement regarding the importance of PPI administration following endoscopy in patients with confirmed peptic ulcer related bleeding. ${ }^{30}$ A meta-analysis of intravenous 
PPI therapy (80 mg bolus followed by $8 \mathrm{mg} / \mathrm{hr}$ ) versus placebo for 72 hours after endoscopic hemostasis demonstrated a significant reduction in rebleeding (number needed to treat $[\mathrm{NNT}]=12$ ), surgery (NNT=28), and mortality ( $\mathrm{NNT}=45)$ in patients who had high-risk endoscopic stigmata (active bleeding, visible vessel, or adherent clot) at the time of their exam. ${ }^{34}$ Other endoscopic stigmata, such as a clean based or flat pigmented spot, have suitably low risk for rebleeding in themselves, and standard oral antisecretory therapy is sufficient for healing. ${ }^{35}$

\section{Eradication of $\boldsymbol{H}$. pylori infection}

$H$. pylori infection is a well-established cofactor in the development of gastroduodenal ulcer disease and a primary independent risk factor for ulcer bleeding in epidemiological studies. ${ }^{36,37}$ Several high-quality publications, including the Maastricht consensus report and a recent Cochrane systematic review, suggest that the inclusion of a PPI along with two (triple therapy) or three (quadruple therapy) antibiotics provides a synergistic effect in the eradication of $H$. pylori and that PPIs are more effective in this role than $\mathrm{H}_{2} \mathrm{RAs}{ }^{38,39}$ This benefit has been ascribed to both increased bioavailability of acid-labile antibiotics ${ }^{40}$ and perhaps the direct inhibition of $H$. pylori growth. ${ }^{7}$

Long-term PPI therapy without eradication of $H$. pylori in infected patients may have potential attendant risks, although this remains controversial. It has been observed that acidsuppression alone alters the pattern of $H$. pylori associated gastritis to favor the gastric corpus and may facilitate the longterm development of atrophic gastritis. ${ }^{41-43}$ Furthermore, there are animal data to suggest that PPI therapy without eradication may accelerate the potential for $H$. pylori to induce gastric carcinoma, though there is no substantive human correlation to this model. ${ }^{44,45}$ These data highlight the potential importance of eradication confirmation in infected patients who will continue antisecretory therapy beyond the short-course of antibiotics for other clinical purposes.

\section{Prevention of NSAID induced gastroduodenal ulcers}

Gastrointestinal (GI) toxicity from NSAIDs, including aspirin, is estimated to account for at least 2,600 deaths in the United States each year. ${ }^{46}$ In addition, the use or misuse of these drugs cause significant morbidity in the form of UGI symptoms, GI bleeding, and increased health care utilization. ${ }^{47}$ A 2008 multisociety guideline ${ }^{48}$ and an American College of Gastroenterology guideline issued in $2009^{49}$ identified patients perceived to be at risk for NSAID induced GI toxicity who should be considered for prophylaxis. Present options for reducing the risk of NSAID associated GI toxicity in patients with obligate use of these agents include: the addition of misoprostol or acid antisecretory therapy, the use of a COX-2 selective NSAID, or any combination of these strategies.

While individual short term studies of $\mathrm{H}_{2} \mathrm{RAs}$ for prevention of NSAID induced ulcers have been published ${ }^{50,51}$ these results have not been consistent or observable over long-term patient follow-up. A meta-analysis of 112 individual RCTs by Koch et al. ${ }^{52}$ suggested that $\mathrm{H}_{2} \mathrm{RAs}$ demonstrated no evidence supporting the use of conventional dose $\mathrm{H}_{2}$ RAs in a prophylactic role although high dose $\mathrm{H}_{2} \mathrm{RAs}$ may be beneficial. ${ }^{53}$ Once daily PPIs, on the other hand, were protective against the development of gastroduodenal ulcers $(\mathrm{OR}=0.35)$ in asymptomatic patients taking low-dose aspirin who underwent endoscopy. ${ }^{54}$

The best data in favor of PPI use come from two multicenter trials of higher-risk patients $(n=1,429)$ taking daily NSAIDs. In these studies, the cumulative percentage of patients who developed ulcers at 6 months was substantially smaller in the group receiving esomeprazole (20 $\mathrm{mg}$ daily) (5.2\%) versus placebo (17\%). In addition, the use of a selective or nonselective COX inhibitor did not seem to impact whether patients were likely to develop an ulcer in the placebo group (17.1\% vs $16.5 \%)$ while PPI co-therapy significantly reduced ulcer formation in both nonselective and selective NSAID users (6.8\% vs $0.9 \%) .{ }^{55}$

\section{Zollinger-Ellison syndrome}

While the ultimate goal for patients in ZES is surgical excision of the neuroendocrine tumor, virtually every individual with this disease requires medical intervention to prevent acidpeptic complications due to the constitutive release of gastrin. ${ }^{56}$ The gastric acid hypersecretion associated with ZES can be controlled effectively using PPIs, though studies involving large numbers of patients are lacking due to the rare nature of this disease.

In a prospective 4-year study of 40 patients with ZES, patients underwent measured acid-output and had clinical endpoints assessed in response to titratable doses of omeprazole. ${ }^{57}$ Most patients in the study were able to have their acid output controlled with a once daily PPI dose, though nine required 60 $\mathrm{mg}$ twice daily for acid reduction. In a separate 13-year series involving 67 patients, greater than 90\% of those enrolled were able to demonstrate long-term symptom control with a titration of lansoprazole (7.5 to $450 \mathrm{mg} /$ day). ${ }^{58}$ Although the usual starting doses for PPIs in ZES are high (typically 60 to $120 \mathrm{mg}$ daily), some patients can be down-titrated as low as $20 \mathrm{mg}$ omeprazole once initial ulcer healing and symptom resolution has occurred..$^{59}$

\section{Erosive esophagitis}

A systematic review of 15 epidemiological studies estimates the prevalence of gastroesophageal reflux disease to be somewhere between 10 and 20 percent in the Western world and around 5 percent in Asia. ${ }^{60,61}$ A subset of symptomatic patients will have endoscopic evidence of erosion, though classification of this finding varies among endoscopists. ${ }^{62}$ PPIs at typical dosages are exceedingly effective at inducing symptom remission and healing erosive esophagitis the overwhelming majority of patients. ${ }^{63,64}$ 
A Cochrane review of 134 trials which included 36,978 patients with erosive esophagitis demonstrated that the acute use of PPIs uniformly provided more rapid healing of esophagitis and symptom resolution compared with $\mathrm{H}_{2}$ RAs and/or prokinetics. This was true regardless of the initial severity of esophagitis and was also independent of dose and treatment duration. In addition, there were no major observable differences in the overall effectiveness or side-effect profile among presently available PPIs for this indication. ${ }^{64}$

PPIs are also highly effective for the maintenance of healing in erosive esophagitis. Perhaps the most widely cited example of this finding was published in a landmark 1995 NEJM paper by Vigneri et al. ${ }^{65}$ In this prospective trial, 175 patients with endoscopically confirmed erosive esophagitis were randomized into one of five treatment arms after initial induction of healing by oral omeprazole (40 mg daily). These arms included: cisapride (10 mg three times per day), ranitidine (150 mg three times per day), omeprazole (20 mg daily), or either antisecretory agent in combination with cisapride. After 12 months of maintenance, omeprazole alone (or in combination with cisapride) was highly significantly superior in maintaining endoscopic remission to ranitidine alone $(\mathrm{p}<0.001)$, cisapride alone $(\mathrm{p}=0.003)$, or both ranitidine and cisapride $(\mathrm{p}=0.03)$.

Although this study suggested that effective doses for maintenance are generally similar to those required to induce initial healing, ${ }^{65}$ this has been subsequently challenged. With few exceptions, such as severe grades of esophagitis, half the healing dose of a PPI is often adequate for maintenance. ${ }^{66}$ Therefore we suggest that the lowest dose of PPI necessary to control symptoms should be the goal of long-term treatment. A transition to on demand therapy may even be appropriate for those who have milder grades of esophageal mucosal injury, as indicated by recent guidelines. ${ }^{67}$

\section{Nonerosive reflux disease}

NERD or endoscopy-negative reflux disease (ENRD) can be a particular challenge for the gastroenterologist. For a myriad of potential reasons, response rates to PPI and antisecretory treatment in general have been inferior in patients who have no endoscopically evident erosive disease. Despite this, PPI treatment for ENRD continues to offer an advantage over placebo $(R R=0.71$, 0.65-0.78) and $\mathrm{H}_{2} \mathrm{RAs}(\mathrm{RR}=0.78,0.62-0.97)$ with respect to heartburn control. ${ }^{68}$ Given the observation that PPIs can be effective even in the absence of endoscopic evidence of injury, many professional societies including the American College of Physicians, ${ }^{69}$ the American College of Gastroenterology, ${ }^{70}$ and the American Society for Gastrointestinal Endoscopy ${ }^{71}$ continue to support a trial of empiric therapy for undifferentiated gastroesophageal reflux disease (GERD) unless alarming clinical indications for immediate upper endoscopy exist. When the absence of significant erosive disease is known, on-demand use of PPIs may be a reasonable option for control in patients who have intermittent but longer term ENRD symptoms. ${ }^{72,73}$

\section{Functional dyspepsia}

Functional dyspepsia, classified as either epigastric pain syndrome or postprandial distress syndrome accounts for approximately $5 \%$ of U.S. primary care visits per year. ${ }^{74}$ There is considerable ongoing debate as to the ideal initial diagnostic and/or management of uninvestigated dyspepsia. Despite this, treatment with omeprazole (20 mg daily) does have the potential to provide complete symptom relief in patients with dyspeptic symptoms and negative endoscopy when compared with placebo (38\% vs $28 \%, \mathrm{p}=0.002$ ). ${ }^{75}$ Low PPI dosages seem to be adequate for this indication, as $15 \mathrm{mg}$ of lansoprazole was observed to provide a similar benefit to $30 \mathrm{mg}$ over a period of 4 and 8 weeks. ${ }^{76}$ A Cochrane review further supports the efficacy of PPI treatment in dyspepsia, and demonstrated a relative risk reduction in symptoms of 14\% (95\% confidence interval, 5\% to 23\%) when compared to placebo. Identifying individual patients who are likely to respond to antisecretory therapy in this setting is difficult, as there is frequently considerable symptom-based overlap between GERD, UGI dysmotility, and gastroduodenal acid-peptic disorders. ${ }^{77}$

\section{CLINICAL LIMITATIONS OF PPIS}

The consistent therapeutic superiority of PPIs over $\mathrm{H}_{2} \mathrm{RAs}$, combined with pervasive distribution of these drugs in both over-the-counter and prescription forms, lends itself to the conclusion that these drugs cannot be improved. On the contrary, up to 50\% of patients taking PPIs for nonerosive GERD are dissatisfied with their treatment due to unresolved symptoms. ${ }^{78}$ Although a multitude of non-PPI related factors may contribute to this inadequate response (UGI motility disorders, duodenogastric-esophageal reflux, visceral hypersensitivity, and patient hyper-vigilance), both the short plasma half-life and necessity for preprandial dosing are significant problems.

Among patients taking PPIs twice per day, nearly 40\% increased their dosage because of persistent nocturnal symptoms. ${ }^{79}$ Overnight recovery of gastric acid secretion, termed "nocturnal acid breakthrough," is frequently encountered with once-daily AM dosing of single release PPIs. ${ }^{80}$ The escalation of dosing to twice daily is often performed in keeping with both the American Gastroenterology Association ${ }^{67}$ and American College of Gastroenterology ${ }^{81}$ practice guidelines. Despite the frequency of this intervention, many patients continue to suffer breakthrough symptoms on a twice-daily regimen. ${ }^{82}$ Pharmacologically, esomeprazole $40 \mathrm{mg}$, given twice per day in healthy volunteers, still results in intragastric $\mathrm{pH}$ below 4 15\% of the day. ${ }^{83}$

The importance of timing of drug dosing is also critically under-appreciated. As discussed previously, PPIs require expression of the proton pump along the parietal cell canaliculi membrane to establish binding. Cytosolic pumps, or those within lip- 
id rafts, will not be accessible and therefore will not be affected. Approximately half of patients do not take their PPIs within 1 hour of breakfast ${ }^{79,82}$ and they may not have been instructed to do so by their physician or pharmacist. ${ }^{84}$ Poor compliance, combined with a narrow window to provide efficacy due to plasma half-life, may be an important cause of PPI failure. ${ }^{78}$

\section{Long-term use of PPIs}

Chronic use of high-dose PPIs is thought to affect the absorption of calcium, magnesium, and vitamin $\mathrm{B}_{12}$ since acid facilitates assimilation and ionization of less soluble forms of dietary calcium and release of food bound vitamin $B_{12}{ }^{85}$ In 2006, a nested, case-controlled series which included more than 13,000 patients from the United Kingdom suggested that the risk of hip fracture was increased with PPI use that exceeded 1 year (OR, 1.44) and was especially increased in those patients who had received high-dose PPIs (OR, 2.65). ${ }^{86}$ Although important, this study has received considerable criticism as there was heterogeneity among patients in study arms and a different prevalence of PPI use (e.g., PUD among fracture patients) which could explain the difference in observed fractures without ascribing causality. A later study which did not include patients who had major risk factors for hip fracture showed no association with PPI use and postulated that the earlier findings may have been due to confounding. ${ }^{87}$ This pattern of retrospective review and analysis has been consistent within the literature and ultimately the risk posed by PPI use seems unsettled. ${ }^{88}$ However, in 2010 the U.S. FDA required all manufacturers of PPIs to revise their product labels to include a warning about possible risk for fractures of the hip, wrist, and spine when used at high dose (more than once daily) or for a long duration (greater than 1 year).

Retrospective observational studies and their meta-analyses have also demonstrated a potential link between the use of PPIs and the development of community acquired pneumonia. ${ }^{89,90} \mathrm{~A}$ meta-analysis which included eight observational studies suggested that PPI use was associated with an 27\% increased risk for either hospital or community acquired pneumonia (OR, 1.27) but that the greatest risk was within 7 days of beginning PPI treatment (OR, 3.95). ${ }^{89}$ This early risk had been demonstrated elsewhere $^{91}$ and is interesting in that the outcome occurs before PPIs attain their full effectiveness. A more recent systematic review of trials including only patients prescribed PPI therapy for new-onset NSAID use revealed no increased risk for pneumonia. In this study, the authors argue that the previously observed association may have been in part due to protopathic bias either from inclusion of GERD patients (a risk factor for pneumonia) or from the misdiagnosis of early symptoms of pneumonia masquerading as GERD. ${ }^{90}$ In the absence of prospective, highquality data, this association remains conjectural and does not influence our prescribing of antisecretory therapy to patients with a solid indication.

Further, there is evidence that PPI use may enhance patient susceptibility to a multitude of enteric infections including small intestinal bacterial overgrowth, ${ }^{92}$ Salmonella, Campylobacter jejuni, and Clostridium difficile. ${ }^{93}$ Infection with C. difficile (CDI) is of particular importance given the associated morbidity and escalating health burden posed by this problem. In 2012, a meta-analysis of 42 observational studies which included over 313,000 patients found that PPI use was associated with both incident (OR, 1.7) and recurrent (OR, 2.5) CDI. ${ }^{94}$ This observation led the U.S. FDA to issue a drug safety communication regarding the importance of PPI exposure, though the impact of both dose and duration of PPI treatment on this association remains unclear.

All PPIs are, to some extent, metabolized by the cytochrome P450 isozyme 2C19 as discussed previously. While this pharmacological property of PPIs has been well known for some time, ${ }^{14}$ it has more recently become a subject of considerable concern. ${ }^{15}$ Specifically, the potential for PPI induced enzyme inhibition to prevent the activation of clopidogrel (Plavix ${ }^{\circledR}$ ) has led to a flurry of warnings, revisions, and publications. This interaction was first observed during in vitro studies which demonstrated that that synchronous administration of omeprazole diminished the effect of clopidogrel on platelet inhibition. In 2009, the FDA recommended avoiding the use of both drugs simultaneously. ${ }^{56}$ Despite this initial concern, there have been no in vivo data which has conclusively connected the use of omeprazole and clopidogrel with adverse clinical outcomes. In addition, this in vivo association has not been reliably demonstrated with other PPIs that are less dependent on 2C19 for their metabolism. ${ }^{95}$ Never the less given our knowledge of the pharmacodynamics, it is our practice to avoid omeprazole (and its stereoisomer, esomeprazole) in patients taking clopidogrel, in favor of alternatives such as lansoprazole, dexlansoprazole, or pantoprazole.

In 2011 the FDA issued a class warning based on 61 individual case reports indicating that prolonged PPI use could result in low magnesium levels. While the mechanism responsible for and true incidence of PPI associated hypomagnesemia are unknown, FDA recommends checking magnesium levels periodically in patients expected to be on prolonged PPI treatment or who take PPIs with medications such as digoxin or drugs that may cause hypomagnesemia (e.g., diuretics). ${ }^{96}$ Other recent FDA mandated PPI class warnings include PPI associated acute interstitial nephritis and the possibility of vitamin $\mathrm{B}_{12}$ deficiency with chronic (more than 3 years) daily PPI use.

\section{Advances in PPI technology}

A number of efforts have been made to overcome the inherent pharmacologic limitations of currently available PPIs, in particular their short plasma half-life (and therefore short duration of effect) and the need for preprandial dosing.

Tenatoprazole, the first imidazopyridine PPI, has demonstrated not only superior inhibitory activity on $\mathrm{H}+/ \mathrm{K}+$ ATPase, but a substantially longer half-life ( 8 hours after a single dose and 
14 after multiple doses) than currently available PPIs. This increase in half-life correspondingly increases the area under the plasma concentration curve (AUC) by over 20-fold, representing increased tissue exposure and thus duration of effect at the parietal cell cannaliculus. ${ }^{97-99}$ While definitive trials of clinical efficacy are still unavailable, this revision to the structure of PPIs has intriguing future potential. Alterations in the formulation of available PPIs have also been utilized as a means of overcoming the challenges posed by short serum half-life. Rabeprazole-ER is a $50 \mathrm{mg}$ capsule which contains 5-distinct $10 \mathrm{mg}$ tablets designed to be degraded and absorbed at intervals throughout the small intestine and colon. In a study of healthy subjects, rabeprazole-ER showed superior control of nocturnal gastric acid secretion when compared to both esomeprazole and conventional delayed-release rabeprazole. ${ }^{11}$ However in two parallel doubleblind studies, rabeprazole-ER was not superior esomeprazole for healing of severe erosive esophagitis (Los Angeles Classification grade $\mathrm{C}$ or D) and relief of associated heartburn ${ }^{100}$ so further clinical development of this compound was discontinued.

Dual-release dexlansoprazole is formulated to release drug in two separate $\mathrm{pH}$ controlled phases. Twenty-five percent of the drug dose is liberated in the proximal small intestine at a $\mathrm{pH}$ of 5.5, with pharmacokinetics (peak plasma concentration of 1 to 2 hours) similar to traditional enteric coated PPIs. This is followed by a second release of 75\% of the drug dose in the more distal small intestine at a $\mathrm{pH}$ of 6.75 which provides a second serum peak at 5 to 6 hours after administration. Like tenatoprazole, this provides an overall increase in the AUC and thereby an overall higher mean 24-hour intragastric $\mathrm{pH}$ than its stereoisomer lansoprazole. ${ }^{12}$ This offers a potential advantage to patients with obligate twice-daily dosing for symptom control, ${ }^{63}$ persistent nocturnal symptoms, ${ }^{101}$ or poor compliance with meal timing.

An alternate strategy to avoid the need for premeal dosing would be the inclusion of a stimulator of gastric acid secretion along with the PPI. Succinic acid exhibits pentagastrin like activity and has been FDA approved as a pharmaceutical excipient. In the past, this substance has been used in the food and beverage industry as an acidity regulator and is "generally recognized as safe." In a preclinical trial of 36 healthy subjects, succinic acid combined with omeprazole $\left(\right.$ Vecam $\left.^{\circledR}\right)$ demonstrated significantly better nocturnal intragastric $\mathrm{pH}$ control than omeprazole alone. ${ }^{102}$ A Phase IIb clinical trial (NCT01059383) evaluating patients with heartburn is currently ongoing.

\section{CONCLUSIONS}

PPIs represent an essential part of the modern gastroenterologist's armament for combating everyday clinical problems. In general, they are highly efficacious in the treatment of acidrelated disorders (Table 3). Despite this, the ubiquitous presence and indiscriminant use of PPIs has led to increased oversight

Table 3. Food and Drug Administration Approved Indications for Proton Pump Inhibitors

\begin{tabular}{|c|c|c|c|c|c|c|}
\hline Indication & Omeprazole & Esomeprazole & Lansoprazole & Dexlansoprazole & Pantoprazole & Rabeprazole \\
\hline \multicolumn{7}{|l|}{ Gastro esophageal reflux disease } \\
\hline Erosive esophagitis-healing & $\checkmark$ & $\checkmark$ & $\checkmark$ & $\checkmark$ & $\checkmark$ & $\checkmark$ \\
\hline Erosive esophagitis-maintenance & $\checkmark$ & $\checkmark$ & $\checkmark$ & $\checkmark$ & $\checkmark$ & $\checkmark$ \\
\hline Nonerosive reflux disease & $\checkmark$ & $\checkmark$ & $\checkmark$ & $\checkmark$ & & $\checkmark$ \\
\hline \multicolumn{7}{|l|}{ Peptic ulcer disease } \\
\hline Duodenal ulcer-healing & $\checkmark$ & & $\checkmark$ & & & $\checkmark$ \\
\hline Duodenal ulcer-maintenance & & & $\checkmark$ & & & \\
\hline Gastric ulcer-healing & $\checkmark$ & & $\checkmark$ & & & \\
\hline NSAID induced ulcers-healing & & & $\checkmark$ & & & \\
\hline NSAID induced ulcers-prophylaxis & & $\checkmark$ & $\checkmark$ & & & \\
\hline Zollinger-Ellison syndrome & $\checkmark$ & $\checkmark$ & $\checkmark$ & & $\checkmark$ & $\checkmark$ \\
\hline \multicolumn{7}{|l|}{ Treatment of Helicobacter pylori } \\
\hline Dual therapy & $\checkmark$ & & $\checkmark$ & & & \\
\hline Triple therapy & $\checkmark$ & $\checkmark$ & $\checkmark$ & & & $\checkmark$ \\
\hline \multicolumn{7}{|l|}{ Pediatric population } \\
\hline Any age (weight based dosing) & $\checkmark$ & $\checkmark$ & $\checkmark$ & & & $\checkmark$ \\
\hline Age greater than 5 years old & & & & & $\checkmark$ & \\
\hline \multicolumn{7}{|l|}{ Special \& off label uses } \\
\hline Nonvariceal acute GI bleeding (IV) & & $\checkmark$ & $\checkmark$ & & $\checkmark$ & \\
\hline Administration via NG tube & & $\checkmark$ & $\checkmark$ & $x$ & & \\
\hline
\end{tabular}

NASID, nonsteroidal anti-inflammatory drugs; GI, gastrointestinal; IV, intravenous; NG, nasogastric. 
among insurers and appropriate concern about the risk of indefinite hypochlorhydria and drug interaction. Careful consideration by the prescriber of appropriate indication, patient cofactors, and the expected dose and duration of treatment is a necessary part of responsible use of any drug, including PPIs.

Although very effective, PPIs are imperfect drugs owing, at least in part, to their pharmacologic limitations. Several novel approaches to overcome these limitations are being explored including the development of a non-benzimidole PPI and sophisticated delivery systems to mitigate the problems associated with their short half-life and obligatory preprandial dosing. Whether these approaches offer a clear clinical advantage or carry with them unanticipated problems, remains to be determined.

\section{CONFLICTS OF INTEREST}

Dr. Peura currently acts as a consultant and member of the speaker bureau for Takeda Pharmaceuticals and Pfizer Pharmaceuticals. Dr. Strand and Dr. Kim have no financial conflicts of interest.

\section{REFERENCES}

1. Farley A, Wruble LD, Humphries TJ. Rabeprazole versus ranitidine for the treatment of erosive gastroesophageal reflux disease: a double-blind, randomized clinical trial: Raberprazole Study Group. Am J Gastroenterol 2000;95:1894-1899.

2. Huang JQ, Hunt RH. pH, healing rate and symptom relief in acidrelated diseases. Yale J Biol Med 1996;69:159-174.

3. U.S. Food and Drug Administration. Proton pump inhibitors: U.S. Food and Drug Administration-approved indications and dosages for use in adults [Internet]. Silver Spring: U.S. Food and Drug Administration; 2014 [cited 2016 Aug 31]. Available from: http:// www.fda.gov/drugs.

4. Chiba N, De Gara CJ, Wilkinson JM, Hunt RH. Speed of healing and symptom relief in grade II to IV gastroesophageal reflux disease: a meta-analysis. Gastroenterology 1997;112:1798-1810.

5. Lassen AT. Acid-related disorders and use of antisecretory medication. Dan Med Bull 2007;54:18-30.

6. Shi S, Klotz U. Proton pump inhibitors: an update of their clinical use and pharmacokinetics. Eur J Clin Pharmacol 2008;64:935951.

7. Klotz U. Pharmacokinetic considerations in the eradication of Helicobacter pylori. Clin Pharmacokinet 2000;38:243-270.

8. Esplugues JV, Marti-Cabrera M, Ponce J. Safety of proton pump inhibitors. Med Clin (Barc) 2006;127:790-795.

9. Maffei M, Desmeules J, Cereda JM, Hadengue A. Side effects of proton pump inhibitors (PPIs). Rev Med Suisse 2007;3:19341936, 1938.

10. Sachs G, Shin JM, Howden CW. Review article: the clinical pharmacology of proton pump inhibitors. Aliment Pharmacol Ther
2006;23 Suppl 2:2-8.

11. Morelli G, Chen H, Rossiter G, Rege B, Lu Y. An open-label, parallel, multiple-dose study comparing the pharmacokinetics and gastric acid suppression of rabeprazole extended-release with esomeprazole $40 \mathrm{mg}$ and rabeprazole delayed-release $20 \mathrm{mg}$ in healthy volunteers. Aliment Pharmacol Ther 2011;33:845-854.

12. Vakily M, Zhang W, Wu J, Atkinson SN, Mulford D. Pharmacokinetics and pharmacodynamics of a known active PPI with a novel Dual Delayed Release technology, dexlansoprazole MR: a combined analysis of randomized controlled clinical trials. Curr Med Res Opin 2009;25:627-638.

13. Williams MP, Pounder RE. Review article: the pharmacology of rabeprazole. Aliment Pharmacol Ther 1999;13 Suppl 3:3-10.

14. Furuta T, Ohashi K, Kamata T, et al. Effect of genetic differences in omeprazole metabolism on cure rates for Helicobacter pylori infection and peptic ulcer. Ann Intern Med 1998;129:1027-1030.

15. Hagymási K, Müllner K, Herszényi L, Tulassay Z. Update on the pharmacogenomics of proton pump inhibitors. Pharmacogenomics 2011;12:873-888.

16. Wolfe MM, Sachs G. Acid suppression: optimizing therapy for gastroduodenal ulcer healing, gastroesophageal reflux disease, and stress-related erosive syndrome. Gastroenterology 2000;118(2 Suppl 1):S9-S31.

17. Howden CW. Optimizing the pharmacology of acid control in acid-related disorders. Am J Gastroenterol 1997;92(4 Suppl):17S19S.

18. Wilder-Smith CH, Ernst T, Gennoni M, Zeyen B, Halter F, Merki HS. Tolerance to oral H2-receptor antagonists. Dig Dis Sci 1990;35:976-983.

19. Prichard PJ, Jones DB, Yeomans ND, Mihaly GW, Smallwood RA, Louis WJ. The effectiveness of ranitidine in reducing gastric acidsecretion decreases with continued therapy. Br J Clin Pharmacol 1986;22:663-668.

20. Hunt RH, Cederberg C, Dent J, et al. Optimizing acid suppression for treatment of acid-related diseases. Dig Dis Sci 1995;40(2 Suppl):24S-49S.

21. Eriksson S, Långström G, Rikner L, Carlsson R, Naesdal J. Omeprazole and H2-receptor antagonists in the acute treatment of duodenal ulcer, gastric ulcer and reflux oesophagitis: a metaanalysis. Eur J Gastroenterol Hepatol 1995;7:467-475.

22. Morgan DG, Burget DW, Howden CW, et al. Rates of duodenal ulcer (DU) healing by drug classes: a meta-analysis. Gastroenterology 1993;104:A150.

23. Poynard T, Lemaire M, Agostini H. Meta-analysis of randomized clinical trials comparing lansoprazole with ranitidine or famotidine in the treatment of acute duodenal ulcer. Eur J Gastroenterol Hepatol 1995;7:661-665.

24. Prakash A, Faulds D. Rabeprazole. Drugs 1998;55:261-267.

25. Fitton A, Wiseman L. Pantoprazole: a review of its pharmacological properties and therapeutic use in acid-related disorders. Drugs 1996;51:460-482.

26. Lauritsen K, Andersen BN, Laursen LS, et al. Omeprazole 20 mg 
three days a week and $10 \mathrm{mg}$ daily in prevention of duodenal ulcer relapse: double-blind comparative trial. Gastroenterology 1991;100:663-669.

27. Lanza F, Goff J, Silvers D, et al. Prevention of duodenal ulcer recurrence with $15 \mathrm{mg}$ lansoprazole: a double-blind placebocontrolled study. The Lansoprazole Study Group. Dig Dis Sci 1997;42:2529-2536.

28. Dammann HG, Walter TA. Efficacy of continuous therapy for peptic ulcer in controlled clinical trials. Aliment Pharmacol Ther 1993;7 Suppl 2:17-25.

29. Katschinski B, Logan R, Davies J, Faulkner G, Pearson J, Langman M. Prognostic factors in upper gastrointestinal bleeding. Dig Dis Sci 1994;39:706-712.

30. Laine L, Jensen DM. Management of patients with ulcer bleeding. Am J Gastroenterol 2012;107:345-60.

31. Barkun AN, Bardou M, Kuipers EJ, et al. International consensus recommendations on the management of patients with nonvariceal upper gastrointestinal bleeding. Ann Intern Med 2010;152:101-113.

32. Barkun A, Bardou M, Marshall JK; Nonvariceal Upper GI Bleeding Consensus Conference Group. Consensus recommendations for managing patients with nonvariceal upper gastrointestinal bleeding. Ann Intern Med 2003;139:843-857.

33. Sreedharan A, Martin J, Leontiadis GI, et al. Proton pump inhibitor treatment initiated prior to endoscopic diagnosis in upper gastrointestinal bleeding. Cochrane Database Syst Rev 2010;(7):CD005415.

34. Laine L, McQuaid KR. Endoscopic therapy for bleeding ulcers: an evidence-based approach based on meta-analyses of randomized controlled trials. Clin Gastroenterol Hepatol 2009;7:33-47.

35. Laine L, Peterson WL. Bleeding peptic ulcer. N Engl J Med 1994;331:717-727.

36. Marshall BJ. Helicobacter pylori. Am J Gastroenterol 1994;89(8 Suppl):S116-S128.

37. Shimada T, Yamagata M, Hiraishi H. Role of Helicobacter pylori eradication in the prevention of peptic ulcer in NSAID users. Nihon Rinsho 2007;65:1824-1829.

38. Malfertheiner P, Megraud F, O'Morain CA, et al. Management of Helicobacter pylori infection: the Maastricht IV/ Florence Consensus report. Gut 2012;61:646-664.

39. Yuan Y, Ford AC, Khan KJ, et al. Optimum duration of regimens for Helicobacter pylori eradication. Cochrane Database Syst Rev 2013;(12):CD008337.

40. Welage LS, Berardi RR. Evaluation of omeprazole, lansoprazole, pantoprazole, and rabeprazole in the treatment of acid-related diseases. J Am Pharm Assoc (Wash) 2000;40:52-62.

41. Lundell L, Havu N, Miettinen P, et al. Changes of gastric mucosal architecture during long-term omeprazole therapy: results of a randomized clinical trial. Aliment Pharmacol Ther 2006;23:639647.

42. Moayyedi P, Wason C, Peacock R, et al. Changing patterns of Helicobacter pylori gastritis in long-standing acid suppression.
Helicobacter 2000;5:206-214.

43. Kuipers EJ, Lundell L, Klinkenberg-Knol EC, et al. Atrophic gastritis and Helicobacter pylori infection in patients with reflux esophagitis treated with omeprazole or fundoplication. N Engl J Med 1996;334:1018-1022.

44. Hagiwara T, Mukaisho K, Nakayama T, Sugihara H, Hattori T. Long-term proton pump inhibitor administration worsens atrophic corpus gastritis and promotes adenocarcinoma development in Mongolian gerbils infected with Helicobacter pylori. Gut 2011;60:624-630.

45. Fox JG, Kuipers EJ. Long-term proton pump inhibitor administration, $\mathrm{H}$ pylori and gastric cancer: lessons from the gerbil. Gut 2011;60:567-568.

46. Gabriel SE, Jaakkimainen L, Bombardier C. Risk for serious gastrointestinal complications related to use of nonsteroidal anti-inflammatory drugs: a meta-analysis. Ann Intern Med 1991;115:787-796.

47. Wallace JL. Nonsteroidal anti-inflammatory drugs and gastroenteropathy: the second hundred years. Gastroenterology 1997;112:10001016.

48. Bhatt DL, Scheiman J, Abraham NS, et al. ACCF/ACG/AHA 2008 Expert Consensus document on reducing the gastrointestinal risks of antiplatelet therapy and NSAID use: a report of the American College of Cardiology Foundation Task Force on Clinical Expert Consensus documents. J Am Coll Cardiol 2008;52:1502-1517.

49. Lanza FL, Chan FK, Quigley EM; Practice Parameters Committee of the American College of Gastroenterology. Guidelines for prevention of NSAID-related ulcer complications. Am J Gastroenterol 2009;104:728-738.

50. Taha AS, Hudson N, Hawkey CJ, et al. Famotidine for the prevention of gastric and duodenal ulcers caused by nonsteroidal antiinflammatory drugs. N Engl J Med 1996;334:1435-1439.

51. Taha AS, McCloskey C, Prasad R, Bezlyak V. Famotidine for the prevention of peptic ulcers and oesophagitis in patients taking low-dose aspirin (FAMOUS): a phase III, randomised, doubleblind, placebo-controlled trial. Lancet 2009;374:119-125.

52. Koch M, Dezi A, Ferrario F, Capurso I. Prevention of nonsteroidal anti-inflammatory drug-induced gastrointestinal mucosal injury: a meta-analysis of randomized controlled clinical trials. Arch Intern Med 1996;156:2321-2332.

53. Tuskey A, Peura D. The use of $\mathrm{H} 2$ antagonists in treating and preventing NSAID-induced mucosal damage. Arthritis Res Ther 2013;15 Suppl 3:S6.

54. Tamura A, Murakami K, Kadota J; OITA-GF Study Investigators. Prevalence and independent factors for gastroduodenal ulcers/ erosions in asymptomatic patients taking low-dose aspirin and gastroprotective agents: the OITA-GF study. QJM 2011;104:133139.

55. Scheiman JM, Yeomans ND, Talley NJ, et al. Prevention of ulcers by esomeprazole in at-risk patients using non-selective NSAIDs and COX-2 inhibitors. Am J Gastroenterol 2006;101:701-710.

56. Jensen RT, Fraker DL. Zollinger-Ellison syndrome: advances in 
treatment of gastric hypersecretion and the gastrinoma. JAMA 1994;271:1429-1435.

57. Maton PN, Vinayek R, Frucht H, et al. Long-term efficacy and safety of omeprazole in patients with Zollinger-Ellison syndrome: a prospective study. Gastroenterology 1989;97:827-836.

58. Hirschowitz BI, Simmons J, Mohnen J. Clinical outcome using lansoprazole in acid hypersecretors with and without ZollingerEllison syndrome: a 13-year prospective study. Clin Gastroenterol Hepatol 2005;3:39-48.

59. Metz DC, Pisegna JR, Fishbeyn VA, et al. Currently used doses of omeprazole in Zollinger-Ellison syndrome are too high. Gastroenterology 1992;103:1498-1508.

60. El-Serag HB, Sweet S, Winchester CC, Dent J. Update on the epidemiology of gastro-oesophageal reflux disease: a systematic review. Gut 2014;63:871-880.

61. Dent J, El-Serag HB, Wallander MA, Johansson S. Epidemiology of gastro-oesophageal reflux disease: a systematic review. Gut 2005;54:710-717.

62. Lee SH, Jang BI, Kim KO, et al. Endoscopic experience improves interobserver agreement in the grading of esophagitis by Los Angeles classification: conventional endoscopy and optimal band image system. Gut Liver 2014;8:154-159.

63. Fass R, Inadomi J, Han C, Mody R, O’Neil J, Perez MC. Maintenance of heartburn relief after step-down from twice-daily proton pump inhibitor to once-daily dexlansoprazole modified release. Clin Gastroenterol Hepatol 2012;10:247-253.

64. Khan M, Santana J, Donnellan C, Preston C, Moayyedi P. Medical treatments in the short term management of reflux oesophagitis. Cochrane Database Syst Rev 2007;(2):CD003244.

65. Vigneri S, Termini R, Leandro G, et al. A comparison of five maintenance therapies for reflux esophagitis. N Engl J Med 1995; 333:1106-1110.

66. Kushner PR, Peura DA. Review of proton pump inhibitors for the initial treatment of heartburn: is there a dose ceiling effect? Adv Ther 2011;28:367-388.

67. Kahrilas PJ, Shaheen NJ, Vaezi MF; American Gastroenterological Association Institute; Clinical Practice and Quality Management Committee. American Gastroenterological Association Institute technical review on the management of gastroesophageal reflux disease. Gastroenterology 2008;135:1392-1413.e5.

68. Sigterman KE, van Pinxteren B, Bonis PA, Lau J, Numans ME. Short-term treatment with proton pump inhibitors, H2-receptor antagonists and prokinetics for gastro-oesophageal reflux disease-like symptoms and endoscopy negative reflux disease. Cochrane Database Syst Rev 2013;(5):CD002095.

69. Shaheen NJ, Weinberg DS, Denberg TD, et al. Upper endoscopy for gastroesophageal reflux disease: best practice advice from the clinical guidelines committee of the American College of Physicians. Ann Intern Med 2012;157:808-816.

70. Katz PO, Gerson LB, Vela MF. Guidelines for the diagnosis and management of gastroesophageal reflux disease. Am J Gastroenterol 2013;108:308-328.
71. Standards of Practice Committee, Lichtenstein DR, Cash BD, et al. Role of endoscopy in the management of GERD. Gastrointest Endosc 2007;66:219-224.

72. Metz DC, Inadomi JM, Howden CW, van Zanten SJ, Bytzer P. On-demand therapy for gastroesophageal reflux disease. Am J Gastroenterol 2007;102:642-653.

73. Pace F, Tonini M, Pallotta S, Molteni P, Porro GB. Systematic review: maintenance treatment of gastro-oesophageal reflux disease with proton pump inhibitors taken 'on-demand'. Aliment Pharmacol Ther 2007;26:195-204.

74. Nyrén 0, Lindberg G, Lindström E, Marké LA, Seensalu R. Economic costs of functional dyspepsia. Pharmacoeconomics 1992;1:312-324.

75. Talley NJ, Meineche-Schmidt V, Paré P, et al. Efficacy of omeprazole in functional dyspepsia: double-blind, randomized, placebocontrolled trials (the Bond and Opera studies). Aliment Pharmacol Ther 1998;12:1055-1065.

76. Peura DA, Kovacs TO, Metz DC, Siepman N, Pilmer BL, Talley NJ. Lansoprazole in the treatment of functional dyspepsia: two double-blind, randomized, placebo-controlled trials. Am J Med 2004;116:740-748.

77. Stanghellini V, Frisoni C. Editorial: reflux, dyspepsia, and Rome III (or Rome IV?). Am J Gastroenterol 2010;105:2632-2634.

78. Fass R, Shapiro M, Dekel R, Sewell J. Systematic review: protonpump inhibitor failure in gastro-oesophageal reflux disease-where next? Aliment Pharmacol Ther 2005;22:79-94.

79. Chey WD, Mody RR, Izat E. Patient and physician satisfaction with proton pump inhibitors (PPIs): are there opportunities for improvement? Dig Dis Sci 2010;55:3415-3422.

80. Tutuian R, Castell DO. Nocturnal acid breakthrough: approach to management. MedGenMed 2004;6:11.

81. DeVault KR, Castell D0; American College of Gastroenterology. Updated guidelines for the diagnosis and treatment of gastroesophageal reflux disease. Am J Gastroenterol 2005;100:190-200.

82. Chey WD, Mody RR, Wu EQ, et al. Treatment patterns and symptom control in patients with GERD: US community-based survey. Curr Med Res Opin 2009;25:1869-1878.

83. Yuan Y, Hunt R. Intragastric acid suppressing effect of proton pump inhibitors twice daily at steady state in healthy volunteers: evidence of an unmet need? Am J Gastroenterol 2008;103(Suppl 1):S50.

84. Chey WD, Inadomi JM, Booher AM, Sharma VK, Fendrick AM, Howden CW. Primary-care physicians' perceptions and practices on the management of GERD: results of a national survey. Am J Gastroenterol 2005;100:1237-1242.

85. Ito T, Jensen RT. Association of long-term proton pump inhibitor therapy with bone fractures and effects on absorption of calcium, vitamin B12, iron, and magnesium. Curr Gastroenterol Rep 2010;12:448-457.

86. Yang YX, Lewis JD, Epstein S, Metz DC. Long-term proton pump inhibitor therapy and risk of hip fracture. JAMA 2006;296:29472953. 
87. Kaye JA, Jick H. Proton pump inhibitor use and risk of hip fractures in patients without major risk factors. Pharmacotherapy 2008;28:951-959.

88. Ngamruengphong S, Leontiadis GI, Radhi S, Dentino A, Nugent K. Proton pump inhibitors and risk of fracture: a systematic review and meta-analysis of observational studies. Am J Gastroenterol 2011;106:1209-1218.

89. Eom CS, Jeon CY, Lim JW, Cho EG, Park SM, Lee KS. Use of acid-suppressive drugs and risk of pneumonia: a systematic review and meta-analysis. CMAJ 2011;183:310-319.

90. Filion KB, Chateau D, Targownik LE, et al. Proton pump inhibitors and the risk of hospitalisation for community-acquired pneumonia: replicated cohort studies with meta-analysis. Gut 2014;63:552-558.

91. Sarkar M, Hennessy S, Yang YX. Proton-pump inhibitor use and the risk for community-acquired pneumonia. Ann Intern Med 2008;149:391-398.

92. Lo WK, Chan WW. Proton pump inhibitor use and the risk of small intestinal bacterial overgrowth: a meta-analysis. Clin Gastroenterol Hepatol 2013;11:483-490.

93. Bavishi C, Dupont HL. Systematic review: the use of proton pump inhibitors and increased susceptibility to enteric infection. Aliment Pharmacol Ther 2011;34:1269-1281.

94. Kwok CS, Arthur AK, Anibueze CI, Singh S, Cavallazzi R, Loke YK. Risk of Clostridium difficile infection with acid suppressing drugs and antibiotics: meta-analysis. Am J Gastroenterol 2012;107:1011-1019.

95. Abraham NS, Hlatky MA, Antman EM, et al. ACCF/ACG/AHA 2010 expert consensus document on the concomitant use of proton pump inhibitors and thienopyridines: a focused update of the ACCF/ACG/AHA 2008 expert consensus document on reducing the gastrointestinal risks of antiplatelet therapy and NSAID use. Am J Gastroenterol 2010;105:2533-2549.
96. U.S. Food and Drug Administration. FDA drug safety communication: low magnesium levels can be associated with longterm use of proton pump inhibitor drugs (PPIs) [Internet]. Silver Spring: U.S. Food and Drug Administration; 2011 [cited 2012 Feb 23]. Available from: http://www.fda.gov/Drugs/DrugSafety/ ucm245011.htm.

97. Galmiche JP, Sacher-Huvelin S, Bruley des Varannes S, et al. A comparative study of the early effects of tenatoprazole $40 \mathrm{mg}$ and esomeprazole $40 \mathrm{mg}$ on intragastric $\mathrm{pH}$ in healthy volunteers. Aliment Pharmacol Ther 2005;21:575-582.

98. Hunt RH, Armstrong D, James C, et al. Effect on intragastric $\mathrm{pH}$ of a PPI with a prolonged plasma half-life: comparison between tenatoprazole and esomeprazole on the duration of acid suppression in healthy male volunteers. Am J Gastroenterol 2005;100:1949-1956.

99. Thomson AB, Cohen P, Ficheux H, et al. Comparison of the effects of fasting morning, fasting evening and fed bedtime administration of tenatoprazole on intragastric $\mathrm{pH}$ in healthy volunteers: a randomized three-way crossover study. Aliment Pharmacol Ther 2006;23:1179-1187.

100. Laine L, Katz PO, Johnson DA, et al. Randomised clinical trial: a novel rabeprazole extended release $50 \mathrm{mg}$ formulation vs. esomeprazole $40 \mathrm{mg}$ in healing of moderate-to-severe erosive oesophagitis. The results of two double-blind studies. Aliment Pharmacol Ther 2011;33:203-212.

101. Fass R, Johnson DA, Orr WC, et al. The effect of dexlansoprazole MR on nocturnal heartburn and GERD-related sleep disturbances in patients with symptomatic GERD. Am J Gastroenterol 2011;106:421-431.

102. Chowers Y, Atarot T, Pratha VS, Fass R. The effect of once daily omeprazole and succinic acid (VECAM) vs once daily omeprazole on 24-h intragastric pH. Neurogastroenterol Motil 2012;24:426431.e209. 